Table 1. MEAN Lenath (CM.) OF First INTERNode OF SEEDLiNGS GROWN IN DARKNESS FOR 13 DAYS INCLUDING THE PERIOD OF SOAEINC

\begin{tabular}{|l|c|c|}
\hline & \multicolumn{2}{|c|}{ Mean length (cm.) of first internode } \\
\cline { 2 - 3 } & $A$ & $B$ \\
\hline $\begin{array}{l}\text { Seeds matured in darkness } \\
\text { Seeds matured in light } \\
\text { Seeds exposed to } 2 \text { hr. light } \\
\text { at 24 hr.after the beginning } \\
\text { of soaking }\end{array}$ & $16 \cdot 4(0 \cdot 837)$ & $13 \cdot 13(0 \cdot 235)$ \\
\hline
\end{tabular}

Column $A$ from the present experiment, column $B$ from previous experiments with commercially grown seeds. Figures in brackets are experiments with commercially
standard errors of the means.

vives the normal long period of inactivity in stored seeds and that the first internode of etiolated seedlings is always partially suppressed by light. It may well be that the higher figure of our controls in the present experiment reflects a reaction to the lower lightintensity in which these seeds were matured as compared with the commercially grown seeds. We hope to verify these inferences by further experiment.

This work has been supported by a grant from the Nuffield Foundation.

G. R. LANE

R. D. BUTLER

Department of Botany,

University of Southampton.

$$
\text { Jan. } 28 .
$$

${ }^{1}$ Lane, G. R., and Butler, R. D., Nature, 181, 1080 (1958).

${ }^{2}$ Gregory, F. G., and Purvis, O. N., Ann. Bot., N.S., 2, 237 (1938).

\section{Differential Reaction of Saprophytic and Parasitic Soil-inhabiting Fungi to Indoleacetic Acid}

INDOkEACETIC acid was shown to be a product of fungus metabolism, when Thimann ${ }^{1}$ in 1935 demonstrated that this was the growth-promoting substance (for higher plants) produced by cultures of Rhizopus suinus. Later, attempts to reproduce in fungi the growth responses to indoleacetic acid found in higher plants were not successful ${ }^{2}$, and interest in this field has been limited. The importance of indoleacetic acid in fungus metabolism has, however, been emphasized by several recent reports, particularly of studies of host-parasite relationships ${ }^{3-6}$.

In the course of experiments on the effects of indoleacetic acid on two saprophytic and two plant parasitic soil-inhabiting fungi, growth of the latter was found to be much more readily inhibited than that of the former. Ophiobolus graminis Sacc., which causes the well-known 'take-all' disease of wheat and other Gramineae, and Fomes annosus Fries, which is a common cause of root and heart rot of conifers, were the two parasites studied. The saprophytes were the two soil fungi Trichoderma viride Pers. ex Fries, and Trichocladium asperum Harz.

Indoleacetic acid at various concentrations was incorporated in a synthetic liquid medium at $p \mathbf{H} \mathbf{5 \cdot 5}$. The medium was dispensed in $25 \mathrm{ml}$. aliquots in 200-ml. Erlenmeyer flasks. A mycelium homogenate in $0.25 M$ sodium chloride was used for inoculating the flasks and growth was measured by determining the weight of dried mycelium which developed. Typical data are given in Table 1.

Neither $T$. viride nor $T$. asperum was significantly inhibited by concentrations of indoleacetic acid up to $100 \times 10^{-5} M$. while $O$. graminis and $F$. annosus were significantly inhibited at concentrations of 10
Table 1. EFFECT OF INDOLEACETIC ACID (IAA) ON GROWTH of FOUR FUNGI

\begin{tabular}{|c|c|c|c|c|}
\hline & \multicolumn{4}{|c|}{ Dry mycelium (mgm.) } \\
\hline IAA $\times$ \\
\hline $10^{-5} M$ & T. viride & T. asperum & O. graminis & F. annosus \\
\hline 0 & $180 \cdot 9$ & $183 \cdot 7$ & $258 \cdot 4$ & $84 \cdot 6$ \\
1.0 & - & $180 \cdot 0$ & $224 \cdot 0$ & $46 \cdot 6$ \\
$10 \cdot 0$ & - & $185 \cdot 5$ & $136 \cdot 5$ & 0 \\
$50 \cdot 0$ & $169 \cdot 8$ & $203 \cdot 8$ & 0 & 0 \\
$100 \cdot 0$ & $188 \cdot 1$ & $183 \cdot 4$ & 0 & 0 \\
\hline L.S.D. at & & & & \\
1.per & & & & \\
cent & - & - & $50 \cdot 4$ & $29 \cdot 1$ \\
\hline
\end{tabular}

and $1 \times 10^{-5} M$ respectively and were completely inhibited at higher concentrations. A number of unidentified saprophytic soil fungi behaved similarly to $T$. viride and $T$. asperum in that the higher concentrations of indoleacetic acid did not significantly reduce growth.

These results may have significance for the parasitic or saprophytic development of these fungi. An extension of these findings will be published elsewhere. E. W. B. WARD A. W. Henry

Department of Plant Science,

University of Alberta, Edmonton. Jan. 15.

${ }^{1}$ Thimann, K. V., J. Biol. Chem., 109, 279 (1935).

2 Leonian, L. H., and Lilly, V. G., Amer. J. Bot., 24, 135 (1937).

${ }^{3}$ Gentile, A. C., and Klein, R. M., Physiol. Plantarum, 8, 291 (1955).

4 Pilet, P. E., Phytopath. Z., 31, 162 (1957).

SShaw, M., and Hawkins, A. R., Can. J. Bot., 36, 1 (1958).

6 Wolf, F. T., Proc. U.S. Nat. Acad. Sci., 38, 106 (1952).

\section{Formation of Purple Pigment in Spirogyra pratensis Cultures}

RECENTLY, investigation of the purple vacuolar pigment of Zygogonium ericetorum Kütz. ${ }^{1}$ has disclosed that it is formed by an association of ferric ions with a gallo-tannin. Similar algal pigments reported as anthocyanin-like ${ }^{2}$ or phycoporphyrin ${ }^{3}$ by previous investigators are probably closely related or identical to the iron-tannin of Zygogonium.

Most of the algal species which produce purple cell sap are found in bogs or swamps where iron is more likely to be available in rather high concentration. In addition to Zygogonium, several other members of the Zygnemataceae produce tannin, and tannin production by Spirogyra has been studied". Thus it is possible that other species, not reported to form purple pigment in Nature, might form pigment under appropriate cultural conditions.

In the course of studies of Spirogyra pratensis Transeau, one of us (A. A.) observed that, in Waris medium containing iron sequestrene, sub-cultures of the alga in which conjugation was occurring produced purple filaments. Similar sub-cultures in soil-water remained pale green. Although extensive tests were not conducted, the distinctive responses to ammonia and to hydrochloric acid ${ }^{1}$ indicated that the pigment which developed in the sub-cultures in Waris medium was similar to that of Zygogonium ericetorum.

Afterwards, vegetative filaments of Spirogyra pratensis were transferred into flasks of soil-water and of Waris medium. Transfers wero made also into small quantitites of soil-water and of Waris medium in watch glasses enclosed within deep Petri dishes. The latter were for the purpose of encouraging conjugation so that we might compare pigment production by sexual and vegetative material. The 